\title{
A Geographic Visualization Approach to Multi-Criteria Evaluation of Urban Quality of Life
}

\section{Claus Rinner}

Ryerson University

Please Cite:

Rinner, C. (2007). A geographic visualization approach to multi-criteria evaluation of urban quality of life. International Journal of Geographical Information Science, 21(8), 907-919.

doi: $10.1080 / 13658810701349060$

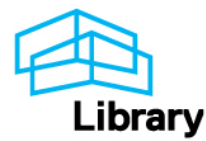




\title{
A Geographic Visualization Approach to Multi-Criteria Evaluation of Urban Quality of Life
}

\author{
CLAUS RINNER \\ Department of Geography, Ryerson University, Toronto, Canada \\ crinner@ryerson.ca
}

This paper proposes to use principles of geographic visualization in conjunction with multicriteria evaluation methods to support expert-level spatial decision-making. Interactive maps can be combined with analytical tools to explore various settings of multi-criteria evaluation parameters that define different decision-making strategies. In a case study, the analytic hierarchy process (AHP) is used to calculate composite measures of urban quality of life (QoL) for neighbourhoods in Toronto. The AHP allows for an interactive exploration of decisionmaking strategies, while offering a view on spatial patterns in the evaluation results. In particular, an interactive blending between a classical and a contemporary QoL model is supported. This feature is used in a pilot study to assess the usefulness of geographic visualization in urban QoL evaluation. Three user interviews provide positive feedback on the utility and usability of the tool that was operated by the investigator.

Keywords: Geographic Visualization, Multi-Criteria Evaluation, Spatial Decision Support, Usability Analysis, Urban Quality of Life 


\section{Introduction}

Geographic visualization (GeoVis) draws on the goals of information visualization, namely presenting complex scientific data in graphical forms in order to facilitate the analyst's understanding of the phenomena underlying those data. In GeoVis, the data being analyzed are spatial in nature and represent problems of geographic scale. The usefulness of the GeoVis approach was shown for the exploratory analysis of massive spatial and spatiotemporal data (DiBiase 1990, MacEachren 1994, Slocum et al. 2005). Fewer attempts have been made to apply GeoVis techniques to processed data - data that represent the output of an analytical process rather than directly representing the characteristics of geographic features or fields. Figure 1 contrasts these two approaches to gaining insight into a dataset vs. gaining insight into an analytical process. While GeoVis from its beginning was conceived as a visual analysis approach, the term "visual analytics” (Wong and Thomas 2004) makes this goal more explicit.

[FIGURE 1]

This paper suggests the combination of visualization tools with specialized analysis tools. It is proposed that principles of GeoVis be used in conjunction with multi-criteria evaluation (MCE) methods to support spatial decision-making. MCE was introduced to spatial decision-making and geographic information systems (GIS) in the 1990s (Malczewski 1999a). MCE methods such as simple additive weighting provide simple analytical tools that are made more useful when combined with interactive cartographic and graphic 
displays. Based on previous work, I will demonstrate how a specific problem in urban quality of life (QoL) evaluation can be addressed by this approach, and will describe an interview-based method to elicit feedback on the usefulness of the geo-visual MCE approach.

The next section will review MCE methods in GIS and introduce GeoVis support for MCE providing map-centred, exploratory decision support. Then, I will discuss common approaches to evaluating the usefulness of GeoVis tools. Next, I will present the evaluation of urban QoL as a spatial decision-making problem. Using a case study of QoL evaluation across neighbourhoods in the City of Toronto, I will describe the use of the analytic hierarchy process (AHP) to define a classical and a contemporary model of QoL, and interactively blend between these two models. Finally, the results from three interviews with senior Geography students (representing domain experts) will be summarized.

\section{Map-Centred Exploration of Multi-Criteria Decision-Making Strategies}

MCE was introduced to GIScience in a variety of applications using different calculation methods (Malczewski 1999a, 2006). In essence, a multi-criteria method creates summary evaluation scores for each decision alternative (e.g. location, area) based on their combined performance in the multiple criteria. In the MCE framework described by Malczewski (1999a), there are various choices to be made by the decision analyst for the parameters of the decision model, including: 
- set of decision criteria;

- standardization method for criteria;

- multi-criteria decision rule; and

- criterion importance weights.

Different choices with respect to these parameters represent different decision-maker preferences and can lead to different evaluation results. Therefore, we can use a GeoVis approach to support a visual sensitivity analysis for decision parameters. This approach allows the analyst to assess differences in evaluation scores based on variations of the input parameters. It is characterised by a simultaneous exploration of MCE parameters and spatial patterns of the corresponding evaluation results. From the above list, the present work focuses on exploring the decision criteria and their importance weights.

GeoVis capitalizes on the power of human image processing to support the discovery of patterns in spatial data and the development of ideas for scientific investigation of geographic phenomena. Interactive functionality for the visual-analytical approach to spatial decision support ranges from map navigation and modifiable symbolization of MCE score maps to multiple, dynamically linked displays of the locations of decision alternatives (decision space) and their non-spatial attributes (criterion space), as well as highlighting of data subsets across these interfaces. 
This GeoVis approach to MCE was introduced by Jankowski et al. (2001) extending earlier work on exploratory spatial decision support (Heywood et al. 1994) and “decision research” (Densham and Armstrong 1995). In particular, Jankowski et al. (2001) demonstrate the benefits of an integrated visualization of decision space and criterion space, which was first suggested by Malczewski (1999b). Andrienko and Andrienko (2001) describe interactive visual tools and map symbols to support decision-making. Andrienko and Andrienko (2002) call for highly interactive tools to visualize the consequences of variations in MCE parameters. The same authors implement an automatic sensitivity analysis based on the variation of criterion weights. Rinner and Malczewski (2002) extend this work to the exploration of multi-criteria decision strategies using GeoVis principles and techniques. Decision strategies in a narrower sense are defined by the settings of the ordered weighted averaging (OWA) decision rule. In a broader sense, we can interpret any combination of the above-listed decision-making parameters as a decision strategy. Malczewski and Rinner (2005) later extended the OWA with linguistic quantifiers, a modification of the underlying conceptual framework that subsequently allows for an improved user interface design.

The analytic hierarchy process (AHP) (Saaty 1980) is a widely used MCE method, which is particularly effective in eliciting user preferences (Malczewski 1999a). AHP assists the decision-maker in simplifying the decision problem by creating a hierarchy of decision criteria. Subsequent operations take place independently at different hierarchy levels with a smaller number of factors to take into account. Furthermore, the method is usually offered with the pair-wise comparison technique that simplifies preference ratings among decision 
criteria. An early example of the use of the AHP method within a GIS context is given in Banai’s (1993) suitability analysis for a landfill location problem. Rinner and Taranu (2006) describe a map-centred interactive AHP implementation to support spatial decisionmaking in the area of public health.

\section{Evaluating the Usefulness of Geographic Visualization Tools}

The increasing popularity of GeoVis tools brings with it a need to evaluate their usefulness for supporting analysts in solving certain tasks. In transferring design principles from human-computer interaction (HCI) research, GeoVis researchers have become aware of the difficulty in measuring the success of GeoVis tools (Fuhrmann et al. 2005). The HCI community defines the usefulness of a software product by its utility and usability. The term utility refers to the ability of a tool to address a task and, thus, is bound by the tool's

functionality. Usability refers to the user's effort in operating the tool and is composed of the following aspects:

- learnability;

- efficiency;

- memorability;

- low frequency and severity of errors; and

- user satisfaction. 
Thus, usability is determined mainly by the presentation of the tool's functionality in its user interface. Various procedures are currently adopted from HCI to increase the usability of GeoVis tools. Fuhrmann and Pike (2005) review the user-centred design method and apply it to the development of collaborative GeoVis tools. The authors use effectiveness, efficiency, and satisfaction as measurements for usability. Similarly, Koua et al. (2006) use effectiveness (task performance), usefulness (appropriateness of functionality), and user reactions as their test measures.

GeoVis however provides particular challenges to usability engineering methods. Tobon (2005) provides an example in which high values of the usability measure of "time required to perform a task", in GeoVis, may be as indicative of high user involvement in the task as it may signal difficulties in using the tool. It must also be noted that the usability measures are based on a complete description of the tasks to be solved. Fuhrmann et al. (2005) acknowledge that in GeoVis user goal achievement is often difficult to measure since a data exploration process usually cannot be pre-structured, even in a usability test environment.

Therefore, an important aspect to consider in evaluating GeoVis tools is the usefulness of the underlying concepts. This approach includes testing GeoVis principles in a new domain before appropriate task descriptions become available, and requires assessment methods that can more easily distinguish between the underlying theoretical framework of a GeoVis tool and user interface concerns. Robinson et al. (2005) adapt a design process from HCI to include user input at various stages of GeoVis tool development. The work domain analysis "represents the initial communication of ideas and requirements between the client ... and 
developers". While this scenario still requires a "client" to be determined, it acknowledges that a rather informal, developer-driven initial design phase may exist.

In the present paper, qualitative feedback from potential users of a GeoVis method is sought based on a prototype demonstration in order to estimate whether the method might be useful in a new application domain: urban QoL evaluation. To achieve an assessment of the method rather than of the prototype software, expert interviews are conducted in which an investigator operates the software while the expert focuses on the domain issues being explored.

\section{Assessment of Urban Quality of Life}

Urban centres worldwide are in a competition concerning the QoL they offer to their residents. QoL rankings are not only a matter of prestige but of attracting and retaining an economically productive workforce. In particular, highly educated and creative people have been shown to be ready to move across boundaries of countries and continents in order to live in high-quality places (Arora et al. 2000).

A difficulty in reacting to urban QoL deficits has been the lack of an agreed-upon definition and measure of QoL. QoL is a multi-faceted problem that has been the subject of considerable attention in the urban geography and planning literature (Massam 2002). Among its multiple dimensions, the QoL of individual persons or groups can be 
distinguished from the QoL of places. QoL may refer either to personal health and wellbeing or to the residential environment.

Beyond the personal level, QoL often has been determined by assessing sets of demographic and socio-economic indicators. Traditionally, wealthy places with educated and employed populations have been considered high-quality (GC 1978, FCM 1999). More recently, indicators such as the cultural and artistic workforce, diversity of origin and sexual orientation, and housing diversity have been taken into account (Florida 2002, Gertler et al. 2002). While most studies discuss these indicators individually (Murdie et al. 1992, van Kamp et al. 2003), MCE offers a distinct option for composite QoL measures (Massam 2002).

While comparisons of QoL between cities are more common than between neighbourhoods within a city, the latter become increasingly important to maintain similar levels of QoL in our growing urban centres. The methodological challenges with assessing urban QoL include the definition of neighbourhoods, the selection of QoL indicators, and the processing of these indicators. The assessment of neighbourhood QoL is not a decision problem per se, but the MCE-based composite QoL scores could inform subsequent political decision-making. With respect to the selection of indicators, a classical and a contemporary model of QoL are suggested that are based on the aggregation of different indicator lists. MCE methods further allow to weight individual QoL indicators. 


\section{Case Study: Quality of Life by Toronto Census Tracts}

Based on Canadian QoL studies (GC 1978, FCM 1999, Massam 2002) and data availability, the socio-economic and demographic variables shown in Table 1 have been selected as QoL indicators for a classical model of QoL. Similarly, the set of variables in Table 2 was selected to build a contemporary model of QoL. The data originate from the Canadian Census 2001 and are taken to represent characteristics of Toronto neighbourhoods.

[TABLE 1]

[TABLE 2]

The AHP method in CommonGIS (Rinner and Taranu 2006) allows the analyst to establish a hierarchy of QoL indicators. On the top level, we split the hierarchy into the two QoL models. Within each model, the indicators were partially grouped by subject (e.g. income) as shown in the left panel of Figure 2. The weighting of individual indicators or groups of indicators within selected branches of the hierarchy is made through sliders or pair-wise comparison. Figure 2 shows the two sliders for weighting (blending) between the two QoL models on the highest level of the hierarchy (centre panel). In this case, full weight is given to the contemporary model. As a result, the indicators belonging to the classical model currently receive weights of zero as indicated by the built-in CommonGIS parallel coordinate plot in the right-hand panel of Figure 2. The different lengths of the parallel axes for indicators in the contemporary model reflect their differing weights. 
[FIGURE 2]

Figure 3 shows the ranks of Census Tracts in the City of Toronto based on two sample multi-criteria evaluations of QoL indicators with equal distribution of weights within indicator groups. The top map in Figure 3 shows the classical QoL model, the bottom map shows the contemporary model.

According to the classical QoL model, the City of Toronto is characterised by a U-shaped pattern of low QoL (brown colour) reaching from the northwest down to the lakeshore at the Toronto Island and harbour areas and up to the northeast. This U shape is known anecdotally to have a larger proportion of disadvantaged population with respect to social and health-related characteristics. High QoL (green colour for best 150 Census Tracts) is found in the wealthy central uptown part of the city and towards the western and eastern suburbs.

The contemporary QoL model (bottom map in Figure 3) yields a significantly different picture characterised by higher QoL in the south-central (downtown) area and lower QoL towards the western and eastern suburbs. The central part of the city is still assessed at high QoL. This pattern reflects the attractiveness of the urban core through its younger and diverse population and higher level of employment in creative occupations. 


\section{Interviews with Domain Experts}

The complex nature of both, the evaluation of urban QoL and the use of the CommonGISbased GeoVis tool led to developing interviews with domain experts in which the GeoVis tool was operated by an investigator while the participant was questioned about urban QoL evaluation. Three interviews were conducted with students representing domain experts. The participants were two senior undergraduate students specializing in urban Geography and a Master of Spatial Analysis student with a research project in the area of urban planning. None of the students had worked with the CommonGIS system before, although one of them had seen a demo of CommonGIS’ interactive mapping functionality in class (but not of its decision support functions).

The interviewer briefly introduced the basic tenets of urban QoL assessment, multi-criteria decision-making with the AHP method, and the CommonGIS software. The Toronto neighbourhood application described above was started and a pre-defined AHP hierarchy with the two QoL models loaded. The socio-demographic variables used as QoL indicators were discussed. Then, the interactive manipulation of weights for QoL indicators and the immediate feedback on the cartographic display of resulting evaluation ranks was demonstrated. Focusing on the weight balance at the top of the indicator hierarchy, i.e. between the two distinct QoL models, the interviewer asked the first question:

1. What weighting between the contemporary and classical models do you see as useful on a city-wide scale, based on the existing hierarchy? 
Next, the interviewer provided the opportunity to identify a neighbourhood of interest and to review the previously preferred weighting scheme:

2. Is there any particular area of interest you would like to examine? If so, how well does the representation reflect your perceptions on a neighbourhood scale?

Next, the participant's opinions on the composition of the indicator hierarchy were collected:

3. Do you accept the default indicator hierarchy? Can you suggest any new weights of attributes within the hierarchy, for one or both of the models? Is the grouping helpful?

4. Are there any indicators that you feel are not adequately represented? Are there any indicators that you feel should not be included in the default hierarchy?

The interview questions 1 to 4 were designed to prompt the participants to think about urban issues using the GeoVis approach, and thus indirectly deduce the usefulness of the proposed method through the observation of their involvement with the domain issues. The final open-ended question related directly to the usefulness of the map-centred QoL evaluation method and asked for suggestions to improve the proposed approach:

5. What are your impressions on the usefulness of this interactive mapping method within a decision support framework? Are there any areas in which the concept of using interactive maps for subjective assessments could be improved? 


\section{Results from the Interviews}

The three participants settled on 65\%/35\%, 75\%/25\%, and 85\%/15\% blendings between the two QoL models, the contemporary and the classical one (question 1). These decisions were made as a result of the operator's blending back-and-forth between the two models in response to the participant's requests while the participant observed the map of ranked city neighbourhoods. Participants appreciated the opportunity to change the choropleth colour scheme to a diverging scheme interactively in order to emphasize the top 50 or top 100 ranks among the 532 Census Tracts representing neighbourhoods. The presence of a street layer was also deemed helpful for orientation purposes, indicating that the participants used information on, or preconceptions of, neighbourhoods within the city rather than going by the overall spatial pattern for the entire city.

When explicitly asked to focus on individual neighbourhoods (question 2), the participants let the operator zoom to one or two areas each: Parkdale, Trinity-Bellwoods, Regent Park, and Keelesdale-Eglinton West. All of these are working-class, low-income, immigrant, and/or areas in transition. After reviewing different weighting options, participants generally tended to revise their blending between the QoL models giving the contemporary model an even higher weight when focusing on these neighbourhoods. Figure 4 shows a stage in the exploration of neighbourhoods along Queen Street West. The mouse cursor

points to Census Tract 0044.00 which extends from north of Queen Street into the area just south of Queen Street where the CN rail track to the south and Dovercourt Road to the east bound the so-called “Queen West Triangle”. As indicated in the popup window next to the 
cursor and in CommonGIS' dot plot of rankings to the right of the maps, this neighbourhood which is currently being redeveloped, improves in rank from 276 to 137 under the classical (left-hand map) and contemporary (right-hand map) models, respectively.

[FIGURE 4]

With respect to the weighting in the default hierarchy, the participants had questions and comments about the variables taken into account in each of the two QoL models (question 3). One participant requested to see the spatial pattern of the proportion of people employed in creative and artistic professions, which could be quickly achieved by moving the weight for this variable up to $100 \%$ effectively reducing all other weights to zero. Concerns were expressed by participants about the simplistic approach of using Census variables to assess QoL, some possibly controversial variables such as immigrant and lone-parent proportions, and the composition of the QoL models.

Question 4 regarding the indicators taken into account in the default hierarchy sparked similar reactions as the previous question. Variables that were more closely inspected with the help of the operator included immigrants, low income, and population change. Indicators considered to be missing included sexual orientation, vehicle ownership, presence of parks or green spaces, and more generally, infrastructure-related indicators to complement socio-demographic factors. 
The responses to questions 3 and 4 underline the difficulty of modelling urban QoL in a quantitative way. At the same time, they seem to indicate that an interactive map-based approach to exploring MCE results can support a critical assessment and revision of decision-making strategies by expert analysts.

Answers to question 5 suggest that the participants generally found the visual approach to analysing QoL patterns to be useful. One subject indicated that "it made it easier to see things" although she noted that she was already familiar with the patterns that appeared. Generally, participants saw a great potential in the application of this method, considering the visual capacities of humans. They also found that the CommonGIS tool seemed easy to use after the "intimidating” setup (selection of data table, MCE method, and loading of predefined hierarchy). The only specific recommendation on the usability of the tool was to combine the map view with the MCE settings in a single window instead of two separate windows.

With respect to the application in urban QoL evaluation, the participants expressed concerns related to the geographic scope, the completeness of QoL models, and the motivation of the potential users. One subject suggested that it was more difficult to establish a “perfect” QoL measure for a large, diverse city such as Toronto in contrast to a smaller geographic area. Somewhat contradictory to this statement, concerns were reiterated from answers to question 4 that the models used did not provide a comprehensive set of indicators for urban QoL. In particular, mapping the locations of certain community services facilities would improve the evaluation of QoL. Furthermore, it was stated that the 
success of this method might depend on the objectives of using it and the expertise of the user in the application domain, in this case the prior knowledge of QoL indicators and their relative importance in a composite measure.

Finally, the subjects also suggested other possible application areas and user groups for the method tested. One participant proposed the use in the physical-environmental area for agricultural suitability assessment, while another envisioned charitable organizations that

seek to understand donor patterns and, more generally, non-governmental organizations that are planning the distribution of service facilities and resources.

\section{Conclusion and Outlook}

The research summarized in this paper deals with the application of geographic visualization principles to spatial decision support. GeoVis allows for the exploration of geographic space and decision space in multi-criteria evaluation. When interactively manipulating MCE settings, analysts can observe the resulting changes in the decision outcome and compare them to their knowledge of the study area. Through this process, a fine-tuning of decision-making strategies that become manifest in the MCE settings can be achieved.

An application of interactive map-based MCE to urban QoL assessment was suggested, in which a specific property of the AHP method is exploited. AHP allows the analyst to blend between different models for QoL thus allowing for a visual comparison of QoL patterns 
across the study area. In a pilot study, this feature was used in interviews with studentexperts to elicit the usefulness of the GeoVis approach to urban QoL evaluation.

Results indicate that the operation of a map-centred decision support tool for QoL evaluation sparked the participants’ imagination, so that they asked the interviewer to run them through various settings in the AHP method, in particular with respect to the blending between the classical and contemporary model. Although participants were knowledgeable about spatial patterns of urban QoL in Toronto, the visual analytics approach to exploring the underlying evaluation was well-received. In subsequent research, a more formal structuring of tasks within urban QoL evaluation should be used to further evaluate GeoVis support.

More generally, this paper aims to contribute to the development and validation of novel GeoVis tools with (simple) analytical decision support functionality. The pilot study will inform further development of tools and processes for decision-centred GeoVis, although the small number of participants and the substitution of domain experts with student participants somewhat limits the generalization of results. This research will further aid in designing more comprehensive case studies to test the usefulness and usability of such tools.

One current research direction aims at studying the role of original attribute values in the standardization and weighting steps in MCE by allowing decision-makers to modify those values; to explore different standardization methods; and to consider attribute value ranges 
when determining criterion weights. As a result of the research presented in this paper, the focus on more detailed geographies seems to assist analysts in revising their initial decision-making strategies. Therefore, a multi-scale approach to map-centred MCE could also be useful, which could be implemented by including principles of spatial online analytical processing into the present method.

\section{Acknowledgements}

Contributions by William Hong, Angela Brinklow, and Jordan Katz to the review of urban QoL concepts, and the data collection and preparation for the two QoL models are gratefully acknowledged. Jordan Katz conducted the interviews with the help of Amrita Hari. A previous version of this paper was presented at the workshop on "Visualization, Analytics \& Spatial Decision Support” at the GIScience 2006 conference. Comments by two anonymous reviewers were helpful in expanding the scope of the workshop paper, while three additional reviewers assisted with clarifying the strengths and limitations of the pilot study. Emily Duncan provided valuable comments for improving the final manuscript. Partial funding for this research was received from the Natural Sciences and Engineering Research Council of Canada and the GEOIDE Network of Centres of Excellence. 


\section{References}

Andrienko, N., and Andrienko, G., 2001, Intelligent Support for Geographic Data Analysis and Decision Making in the Web. Journal of Geographic Information and Decision Analysis 5(2):115-128.

Andrienko, N., and Andrienko, G., 2002, Informed Spatial Decisions through Coordinated Views. Information Visualization 2(4):270-285.

Andrienko, G., Andrienko, N., Bernardo, F., Hipolito, J., Kretschmer, U., and Voss, H., 2002, Testing the usability of interactive maps in CommonGIS. Cartography and Geographic Information Science 29(4):325-342.

Arora, A., Florida, R., Gates, G.J., and Kamlet, M., 2000, Human Capital, Quality of Place and Location. Report prepared on behalf of Heinz Endowments and Sustainable Pittsburgh. September 2000. Available online at http://www.pittsburghregion.org/public/cfm/library/reports/humancapital.pdf [last access: 14 May 2006]

Banai, R., 1993, Fuzziness in geographical information systems: Contributions from the analytic hierarchy process. International Journal of Geographical Information Systems, 7(4):315-329.

Densham, P., and Armstrong, M.P., 1995, Human-computer interaction: considerations for visual interactive locational analysis. In T.L. Nyerges, D.M. Mark, R. Laurini, and M.J. Egenhofer: Cognitive Aspects of Human-Computer Interaction for GIS (Kluwer). 
DiBiase, D. 1990, Visualization in the earth sciences. Earth and Mineral Sciences, Bulletin of the College of Earth and Mineral Sciences, Pennsylvania State University 59(2):13-18.

FCM (Federation of Canadian Municipalities) (1999) The FCM Quality of Life Reporting System: Quality of Life in Canadian Communities (Ottawa).

Florida, R., 2002, The Economic Geography of Talent. Annals of the Association of American Geographers 92(4):743-755.

Fuhrmann, S., Ahonen-Rainio, P., Edsall, R.M., Fabrikant, S.I., Koua, E.L., Tobon, C., Ware, C., and Wilson, S., 2005, Making Useful and Usable Geovisualization: Design and Evaluation Issues. In J. Dykes, A.M. MacEachren, and M.-J. Kraak, Exploring Geovisualization (Amsterdam: Elsevier).

Fuhrmann, S., and Pike, W., 2005, User-centred Design of Collaborative Geovisualization Tools. In J. Dykes, A.M. MacEachren, and M.-J. Kraak, Exploring Geovisualization (Amsterdam: Elsevier).

Gertler, M.S., Florida, R., Gates, G., and Vinodrai, T., 2002, Competing on Creativity: Placing Ontario's Cities in North American Context. A report prepared for the Ontario Ministry of Enterprise, Opportunity and Innovation and the Institute for Competitiveness and Prosperity, November 2002. Available online at http://www.utoronto.ca/progris/Competing\%20on\%20Creativity\%20in\%20Ontario \%20Report\%20(Nov\%2022).pdf [last access: 14 May 2006]

GC (Government of Canada) (1978) Urban Indicators: Statistical Profiles of Quality of Life for Canadian Cities. Revised ed., Ottawa: Ministry of State of Urban Affairs. 
Heywood, I., Oliver, J., and Tomlinson, J., 1994, Building and Exploratory Multi-Criteria Modelling Environment for Spatial Decision Support. In Proceedings of the EGIS'94 conference (Paris).

van Kamp, I., Leidelmeijer, K., Marsman, G., and de Hollander, A., 2003, Urban Environmental Quality and Human Well-Being Towards a Conceptual Framework and Demarcation of Concepts; a Literature Study. Landscape and Urban Planning 65:5-18.

Jankowski, P., Andrienko, N., and Andrienko , G., 2001, Map-centered exploratory approach to multiple criteria spatial decision making. International Journal of Geographical Information Science 15(2):101-127.

Jankowski, P., and Nyerges, T., 2001, GIS-Supported Collaborative Decision Making: Results of an Experiment. Annals of the Association of American Geographers 91(1):48-70.

Koua, E.L., MacEachren, A.M., and Kraak M.-J., 2006, Evaluating the usability of visualization methods in an exploratory geovisualization environment. International Journal of Geographical Information Science 20(4): 425-448.

MacEachren, A.M., 1994, Some Truth With Maps: A Primer on Symbolization and Design (Washington, DC: Association of American Geographers).

MacEachren, A.M., Brewer, I., 2004, Developing a conceptual framework for visuallyenabled geocollaboration. International Journal of Geographical Information Science 18(1):1-34.

Malczewski, J., 1999a, GIS and Multicriteria Decision Analysis. New York: John Wiley 
Malczewski, J., 1999b, Visualization in multicriteria spatial decision support systems. Geomatica, 53:139-147

Malczewski, J., Rinner, C., 2005, Exploring Multicriteria Decision Strategies in GIS with Linguistic Quantifiers: A Case Study of Residential Quality Evaluation. Journal of Geographical Systems 7(2):249-268.

Malczewski, J., 2006, GIS-based multicriteria decision analysis: a survey of the literature, International Journal of Geographical Information Science 20(7):703-726

Massam, B.H., 2002, Quality of life: public planning and private living. Progress in Planning 58(3):141-227.

Murdie, R., Rhyne, D., and Bates, J., 1992, Modeling Quality of Life Indicators in Canada: A Feasibility Analysis (Ottawa: Centre for Future Studies in Housing and Living Environments).

Rinner, C., and Malczewski, J., 2002, Web-enabled spatial decision analysis using Ordered Weighted Averaging (OWA). Journal of Geographical Systems 4(4):385-403.

Rinner, C., and Taranu, J., 2006, Map-Based Exploratory Evaluation of Non-Medical Determinants of Population Health. Transactions in GIS 10(4):633-649.

Robinson, A. C., Chen, J., Lengerich, E. J., Meyer, H. G., MacEachren, A. M., 2005, Combining Usability Techniques to Design Geovisualization Tools for Epidemiology. Cartography and Geographic Information Science 32(4):243-255.

Saaty, T.L., 1980, The Analytic Hierarchy Process (New York: McGraw-Hill).

Slocum, T.A., McMaster, R.B., Kessler, F.C. and Howard, H.H., 2005, Thematic Cartography and Geographic Visualization, 2nd ed. (Prentice Hall). 
Tobon, C., 2005, Evaluating Geographic Visualization Tools and Methods: An Approach and Experiment Based upon User Tasks. In J. Dykes, A.M. MacEachren, and M.-J. Kraak, Exploring Geovisualization (Amsterdam: Elsevier).

Wong, P.C. and Thomas, J., 2004, Visual Analytics, IEEE Computer Graphics and Applications 24(5):20-21 (Guest Editors’ Introduction). 


\section{LIST OF FIGURES}

Figure 1: Gaining insight through visualization of a massive dataset vs. gaining insight through visualization of massive output of an analytical process.

Figure 2: Dialog for AHP parameter setting. Hierarchy is shown on the left; blending between the two models on the shown in centre panel (full weight given to the contemporary model); CommonGIS’ parallel coordinate plot for all QoL indicators shown in right-hand panel.

Figure 3: Multiple choropleth maps showing the ranks of the 532 Census Tracts in the City of Toronto when applying the two QoL models (top - classical model, bottom contemporary model). The best 150 ranks are shown in green, the remaining ranks in brown with darker tones representing lower (worse) ranks.

Figure 4: Multiple choropleth maps showing the ranks of Census Tracts in the Queen Street West neighbourhood under the two QoL models (left - classical model, right contemporary model). The reference value and break point for the colour scheme is set at rank 150 with best ranks shown in green. 

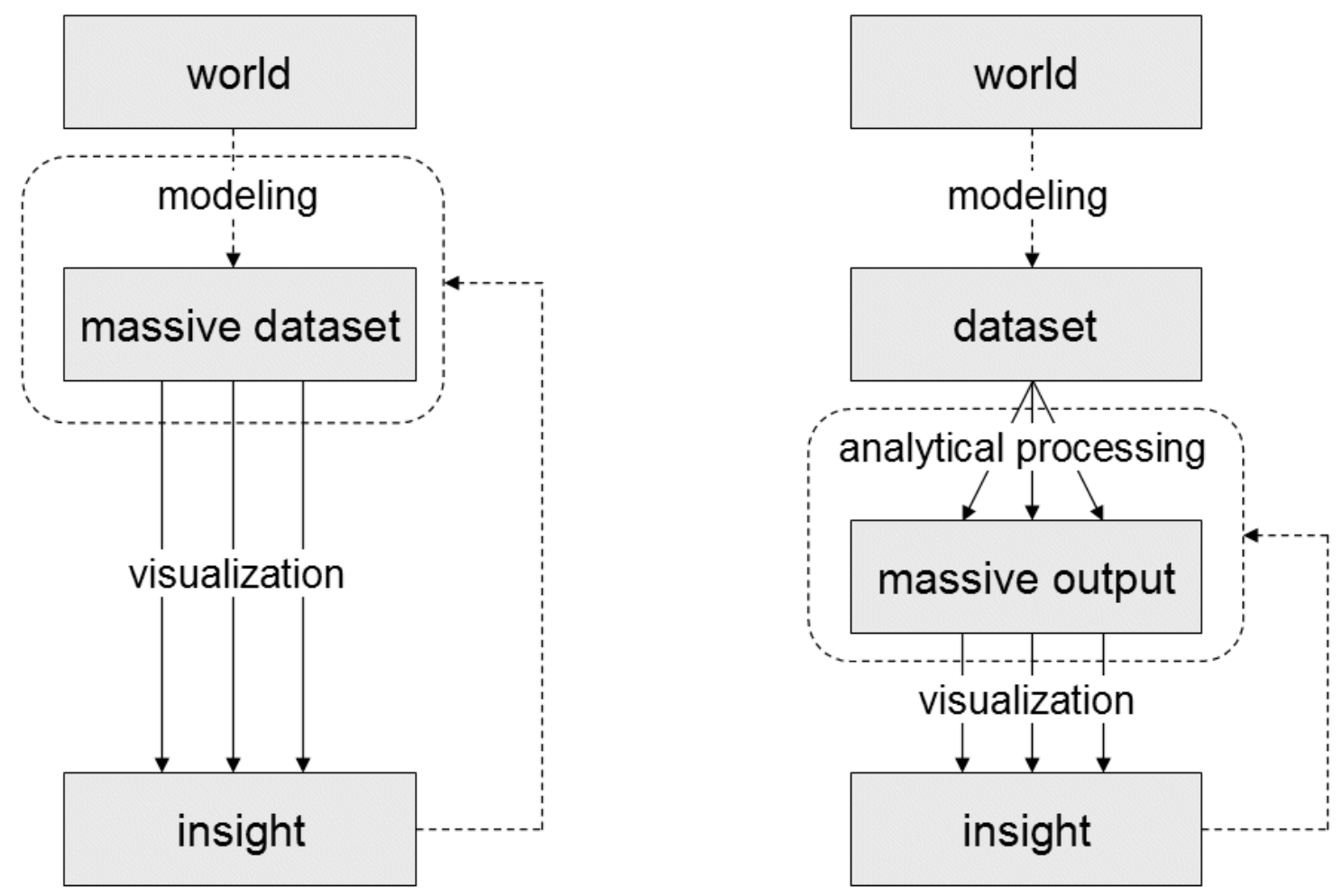

Figure 1: Gaining insight through visualization of a massive dataset vs. gaining insight through visualization of massive output of an analytical process. 


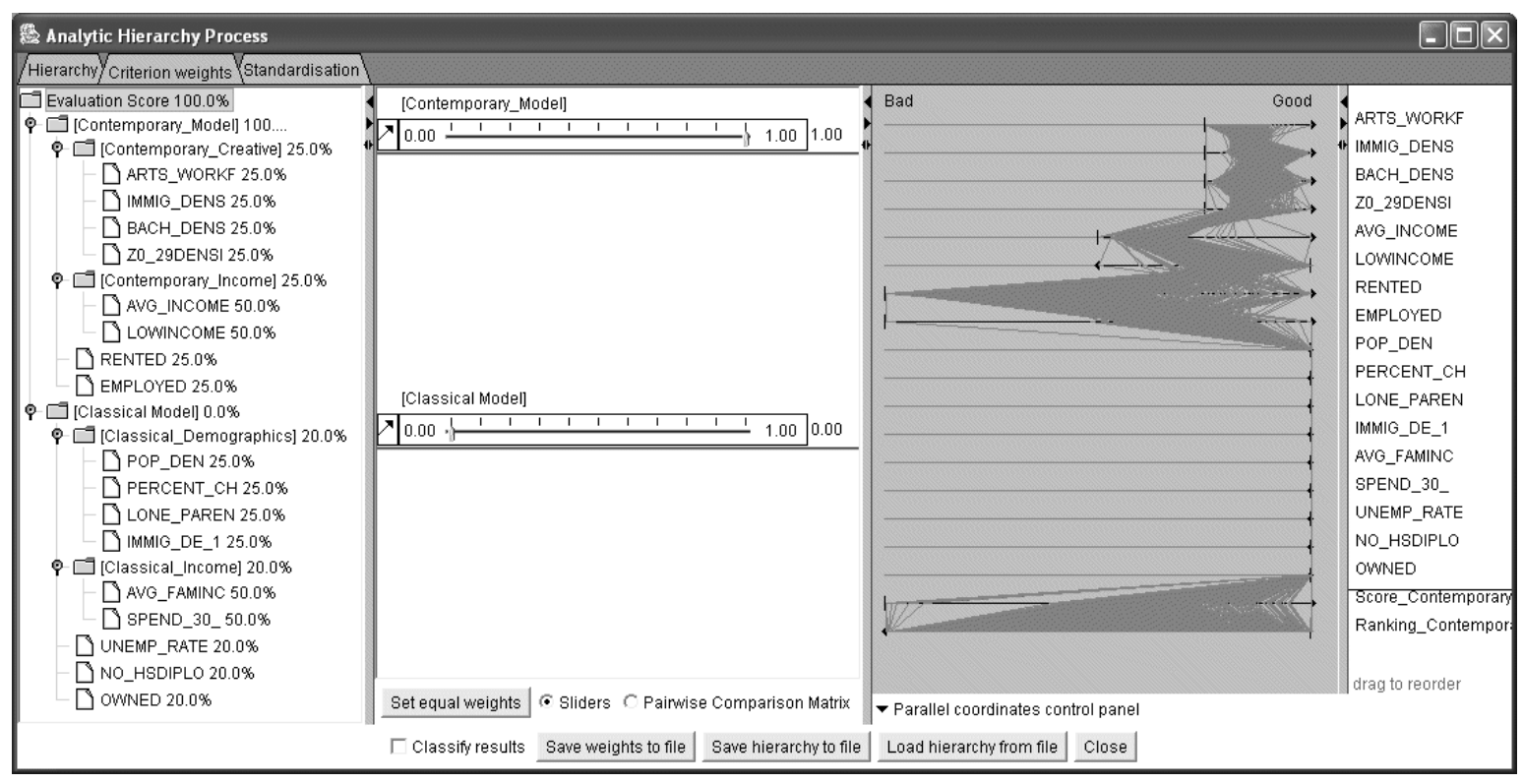

Figure 2: Dialog for AHP parameter setting. Hierarchy is shown on the left; blending between the two models on the shown in centre panel (full weight given to the contemporary model); CommonGIS’ parallel coordinate plot for all QoL indicators shown in right-hand panel. 


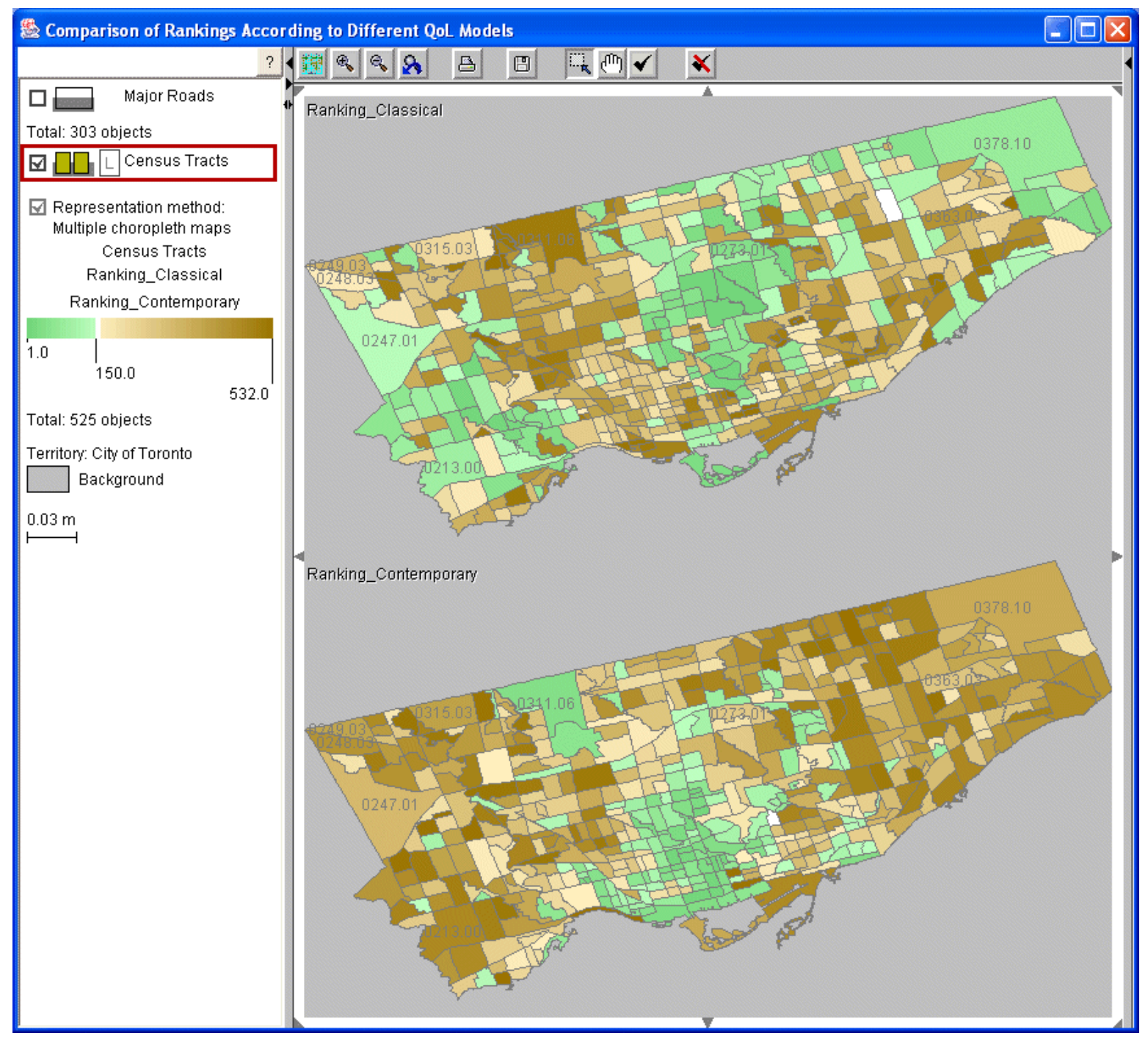

Figure 3: Multiple choropleth maps showing the ranks of the 532 Census Tracts in the City of Toronto when applying the two QoL models (top - classical model, bottom contemporary model). The best 150 ranks are shown in green, the remaining ranks in brown with darker tones representing lower (worse) ranks. 


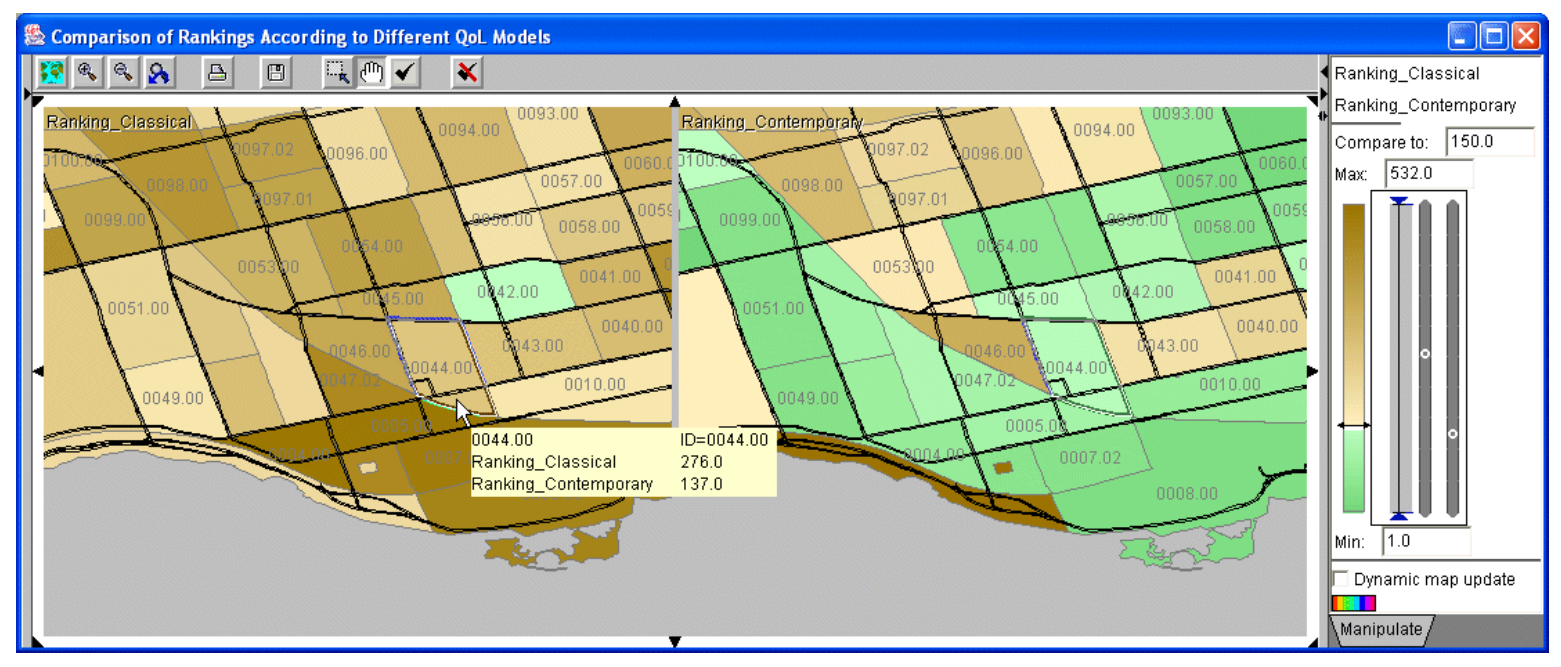

Figure 4: Multiple choropleth maps showing the ranks of Census Tracts in the Queen Street West neighbourhood under the two QoL models (left - classical model, right contemporary model). The reference value and break point for the colour scheme is set at rank 150 with best ranks shown in green. 


\section{LIST OF TABLES}

Table 1: Classical QoL indicators (proportions of a corresponding total population).

Table 2: Contemporary QoL indicators (proportions of a corresponding total population). 
Table 1: Classical QoL indicators (proportions of a corresponding total population).

\begin{tabular}{|c|c|}
\hline Benefit criteria (to be maximized) & Cost criteria (to be minimized) \\
\hline Population change & Population density \\
\hline Ownership of dwellings & Lone-parent families \\
\hline Average household income & Spending $30 \%$ or more of income on housing \\
\hline Owned dwellings & Unemployment rate \\
\hline Immigrants & Population without a highschool diploma \\
\hline
\end{tabular}


Table 2: Contemporary QoL indicators (proportions of a corresponding total population).

\begin{tabular}{|c|c|}
\hline Benefit criteria (to be maximized) & Cost criteria (to be minimized) \\
\hline Arts and culture workforce & Incidence of low income \\
\hline People between the age of 20 and 29 & \\
\hline Bachelor's degree or higher & \\
\hline Employment rate & \\
\hline Average individual income & \\
\hline Diversity of housing (rented dwellings) & \\
\hline Immigrants & \\
\hline
\end{tabular}

